\title{
Detailed Model of a Hydromechanical Double Clutch Actuator with a Suitable Control Algorithm
}

\author{
Sebastian Nowoisky Chi Shen Clemens Gühmann \\ Technische Universität Berlin \\ Chair of Electronic Measurement and Diagnostic Technology \\ Sekr. EN 13, Einsteinufer 17, 10587 Berlin \\ \{ sebastian.nowoisky@,c.shen@mailbox., clemens.guehmann@\}tu-berlin.de
}

\begin{abstract}
This paper presents the detailed model of a double clutch actuator with a suitable control algorithm. Firstly, there is an introduction into the theory of a double clutch transmission and the aim of this project. The simulation model with a Dymola ${ }^{\circledR}$ and a MATLAB ${ }^{\circledR} /$ Simulink ${ }^{\circledR}$ part is discussed. The library of a vehicle model with a highly detailed hydromechanical clutch is introduced, which includes models with different levels of detail. The modeling of the hydraulic and the mechanic parts of the clutch actuator is discussed, concentrating on the problem of determining the parameters of the actuator modules e.g., the hydraulic valves. Some parts could not be used from existing Dymola ${ }^{\circledR}$ libraries, in those cases, new models are created based on Modelica code.

A translational lever is pictured with its source code. Furthermore the non-linear behavior of the clutch actuator and control design is described. To verify this model and the suitable closed loop controller, the algorithm is tested with an up-shift cycle in a vehicle model with a double clutch transmission. The simulation results are presented with a global view of the driver inputs, the speed, the torque of the vehicle model and the gear status. Additionally the local view of the clutch actuator is shown with the cylinder pressure, the clutch position and the clutch capacity (torque). Finally there is a summary and an outlook on the further development of this library.
\end{abstract}

keywords: double clutch transmission, powertrain, clutch, hydraulic, transmission actuator

\section{Introduction}

A modern powertrain with a double clutch transmission (DCT) combines the comfort of an automated transmission with the efficiency of a manual transmission. Moreover, an uninterrupted shift process, a very good ride comfort and easy handling are considerable characteristics of an automated transmission with double clutches [1, 2].

The double clutch transmission is similar to the hardware design of a manual transmission. Instead of one input shaft for the clutch, a double clutch transmission has two separated shafts with odd and even gears. The two clutches can be continuously changed from one input shaft to the other. The result is an automated and uninterrupted shift process. The transmission conforms to different driving situations. In other words, the shift process changes, depending on the driving situation.

The clutch control system is very important in relation to driving behavior. When the vehicle accelerates very fast, the clutch is used to control the speed by means of a higher clutch capacity ${ }^{1}$. For effortless driving, the input torque is followed by the torque capacity of the clutch. In this case, the speed is controlled by the engine controller.

Nowadays software functions for drive train applications are developed and tested in the model based Vprocess [3]. To develop software for the nonlinear and complex hardware a detailed model is necessary.

The clutch actuator consists of several non-linear subsystems e.g. the hydraulic valves or the mechanical disc spring of the clutch. These parts have a hysteresis behavior. To get a detailed clutch model, the existing libraries e.g. Powertrain- or Vehicle Interfaces-Library have been expanded. Important variables like position

\footnotetext{
${ }^{1}$ The clutch transfers the torque only, and this torque is termed capacity.
} 
and torque (capacity) have been integrated.

In this paper we present the modeling, the control and the simulation of a double clutch transmission with a highly detailed model of hydromechanical clutch actuator. First, the model of the vehicle library with the gear set is presented which comprises the hydraulic and mechanic parts. In section 3, the control algorithm for the hydromechanic clutch actuator is discussed. Then, in section 4, the suitability of the models and of the controls is demonstrated in a simulation runs.

\section{Modeling}

The modeling of the double clutch transmission and the clutch actuator is based on a real transmission for mid-size cars. This transmission is a seven speed transmission with a dry double clutch and a torque load up to $250 \mathrm{Nm}$.

For the modeling, two common tools are used. The code of the Transmission Control Unit (TCU) and the Engine Control Unit (ECU) had been developed with MATLAB $^{\circledR} /$ Simulink ${ }^{\circledR}$. The powertrain and the drive environment is modeled with Dymola ${ }^{\circledR}$. For the interaction between both models, an interface is defined. The interaction between the tools is pictured in figure 1. For the simulation the Dymola ${ }^{\circledR}$ powertrain model is included as an embedded s-function in the MATLAB ${ }^{\circledR} /$ Simulink ${ }^{\circledR}$ model. The model library

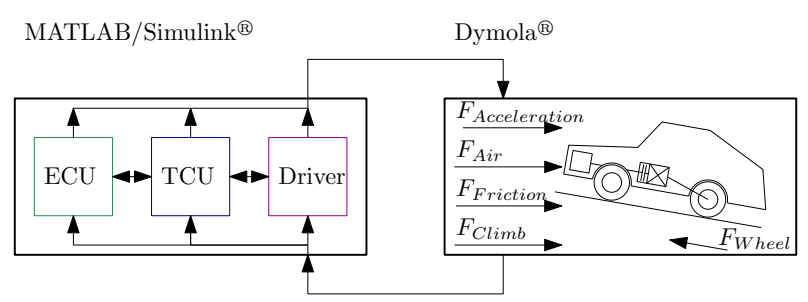

Figure 1: Structure of the powertrain and control model

has common parts such as the User Guide with information for the users and the Examples or the Interfaces. The Interfaces are models with an input and output description, for each sub-module of the transmission model. In the Engine module, there is an engine model based on a simple look-up table. The Transmission module has several sub modules, which are shown in the second row of figure 2. The Library is used for research and teaching, hence there are two different designs of the transmissions in the Gearset module. Some models have different levels
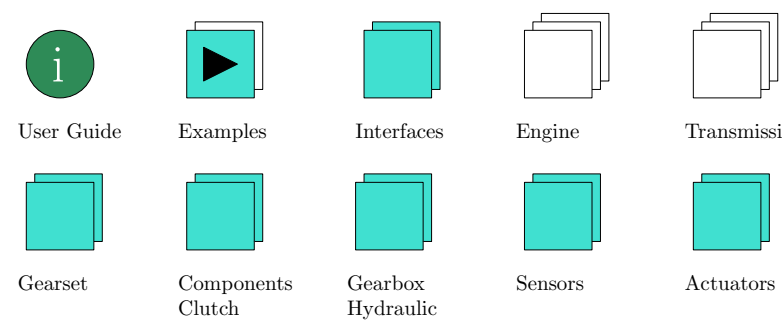

Engine

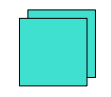

Sensors

Transmission

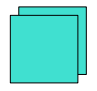

Actuators

\section{Figure 2: Modules of the DCT Vehicle Library}

of detail. For example, a pair of gears exists as a plain and as a complex model. The plain model consists of the ratio and the inertia of the toothed wheel. The complex model gear losses and bearing friction are considered. The friction element corresponds to the current transmission design. The Components Clutch module is a top level module for this topic. This module implies several clutch models with a simple ideal model and a detailed hydromechanical model. The Gearbox Hydraulic module includes the models with the hydraulic components of the transmission, for instance the hydraulic supply, valves and the clutch cylinder. Furthermore the clutch models include mechanical parts such as the lever or the disc spring. These mechanical parts are components of the Actuator module. In the Sensor module there are several types of sensors to measure the torque, the speed and the acceleration.

Some blocks of the vehicle model are derived from the Powertrain library, e.g., the vehicle model or the drive environment. The Interfaces are derived from a former research project [4]. The hydraulic part is modeled with the Hydraulic Library (HyLib) from Modelon [5].

\subsection{Hydraulic Components}

The hydraulic components control and moves the clutch plates in the transmission. Because of, the high energy density, a hydraulic supply is used for midsize cars [6]. An electrical external toothed gear pump supplies the actuator with the hydraulic energy. The pump is switched on and off depending on the current pressure level with a hysteresis switch. The typical pressure supply for a small transmission is approximately 50 bar. This pressure is limited by two 'three port valves' to a level of approximately 16 bar. This pressure level oscillates in a smaller range than the original bang bang controlled hydraulic supply. Furthermore these valves separate the pressure for the odd 


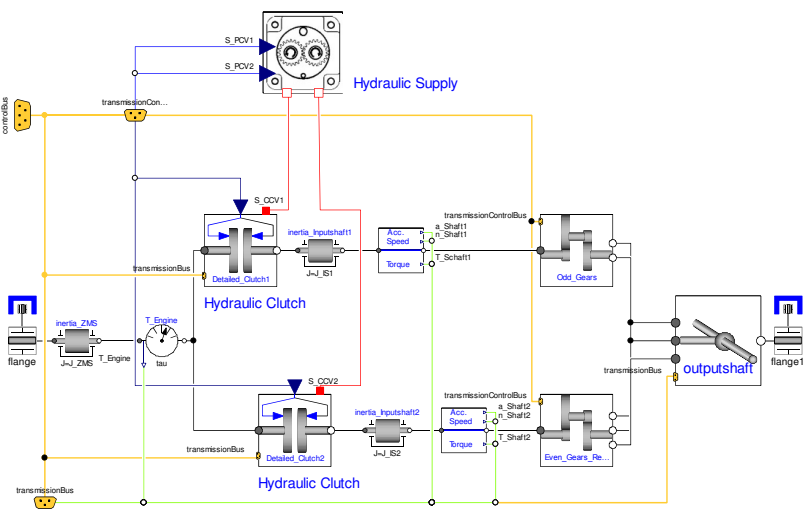

Figure 3: Model of the transmission with replaceable modules

and even gears and the two clutches. Behind this, six other valves control the actuators to set the gears or the clutches. The position between the friction plates of the clutch is set by a single acting cylinder. The model of the double clutch transmission with the hydraulic supply is shown at the top of figure 3. Underneath the hydraulic supply, the detailed model of the hydraulic clutch system can be seen. Each system is replaceable by using the defined interfaces. The parameters correspond to values from literature of similar transmissions [7, 8, 9]. Some parameters were determined at the transmission by means of measurement.

\subsection{Mechanic Components}

The input of the mechanic interface for the hydraulic clutch actuator is a lever that changes the position of the clutch. The rod of the hydraulic cylinder moves outward when the chamber is filled with oil and simultaneously the rod presses against a lever. The force is transferred from the rod to the clutch disc. This lever system described above, is used to control the double clutch capacity. Without hydraulic pressure the clutch is automatically opened. In this instance, the clutch capacity can not be built up anymore, in order to protect the clutch system.

The model of the clutch lever is made up of two rods. One rod is fixed on the top, and the other is fixed in the middle. Figure 4 shows two separately modeled levers.

According to the different lengths of the rods, the model of the rod with top-fix and middle-fix are expressed by Modelica as follows:

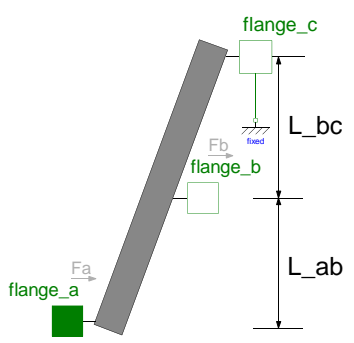

(a) lever model with topfix

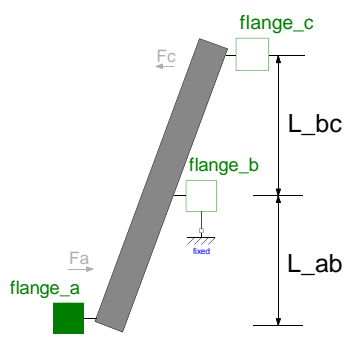

(b) lever model with middle-fix
Figure 4: The two sub models of the lever

Code example for Lever_TopFix (figure 4 a) model Lever_TopFix

Modelica. Mechanics. Translational. Interfaces.Flange_a flange_a

Modelica. Mechanics. Translational. Interfaces.Flange_b flange_b

Modelica. Mechanics. Translational. Interfaces.Flange_b flange_c

Modelica. Mechanics. Translational. Components. Fixed fixed

parameter Modelica.SIunits. Length L_ab;

parameter Modelica.SIunits. Length L_bc; equation

flange_b.f $=-$ flange_a.f $*\left(\left(L_{-} a b+L_{-} b c\right) / L_{-} b c\right)$;

flange_b.s=flange_a.s*(L_bc/( L_ab+L_bc $))$; end Lever_TopFix;

The code for the lever model with the middle fix is similar to the top-fix model, only the equation is different. Every flange of the model provides two types of information: one is the displacement which is described in model with the character - 'flange_x.s', the other is the force, which is described with the character - 'flange_x.f'.

The force within the clutch is transfered by the two levers having two pivot points. The second clutch is modeled similar to the first clutch. In contrast to the first model, the two rods are modeled with the top-fix model. Figure 5 shows an example for modeling the lever mechanism of the first clutch. This lever model consists of two sub-models, which are described in figure 4. The first model (top-fix) output port is connected with the second model (middle-fix) input port. The lever works against the disc spring which has a non-linear behavior [10]. The behavior of the disc spring is modeled by some look-up tables. Within the front range of the clutch position the lever presses the pressure plate against the central plate. The clutch disc is between both plates. As long as the clutch disc does not touch the central plate the spring force increases linearly. When the clutch disc touches the central plate (touch point) the spring force starts to decrease. In or- 


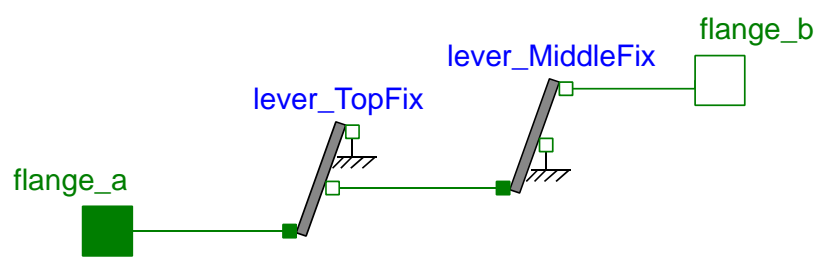

Figure 5: Lever mechanism for clutch 1

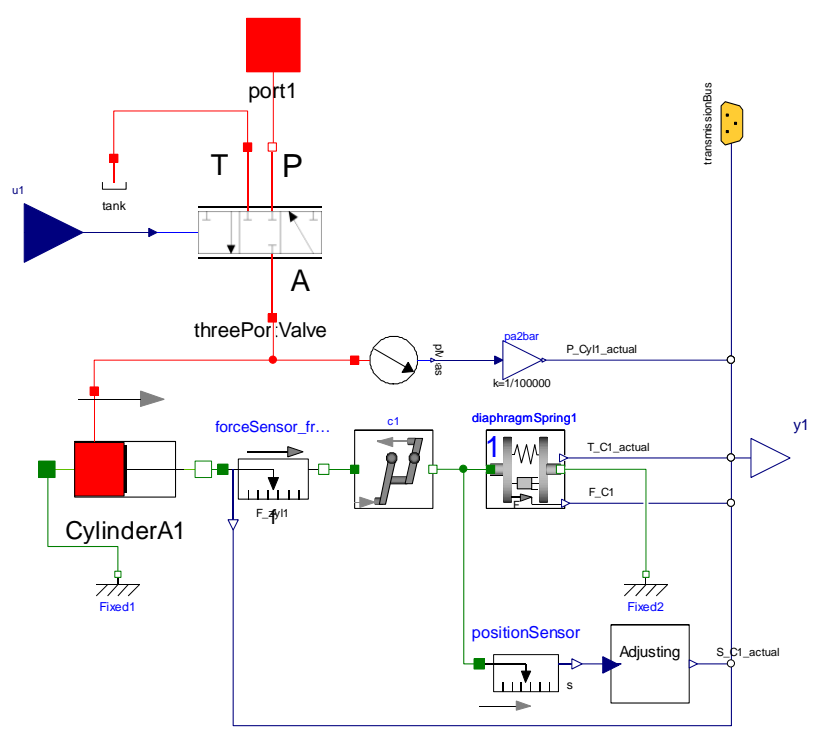

Figure 6: Detailed Clutch Model

der to disengaging the clutch, the parameters change to a lesser value because of the hysteresis of the disc spring [11].

Both the hydraulic one and the mechanic clutch system are presented in figure 6. The output of the model is the position of the lever. Furthermore the pressure of the cylinder, the force and the torque of the clutch system are also shown.

\section{Control}

There is an air clearance between the clutch disc and the clutch housing. Before the clutch torque builds up, the hydraulic system has to be filled with oil to generate the necessary pressure in the clutch cylinder. Then the clutch plates come together up to the touch point and the clutch torque can be built up. The time lag of the clutch system is minimized by using the pre-fill function. This function is active from a shift request up to the touch point of the clutch (as shown in figure 7 phase II).

The behavior of the actuators is derived from the literature [12]. The control of the clutch can be divided

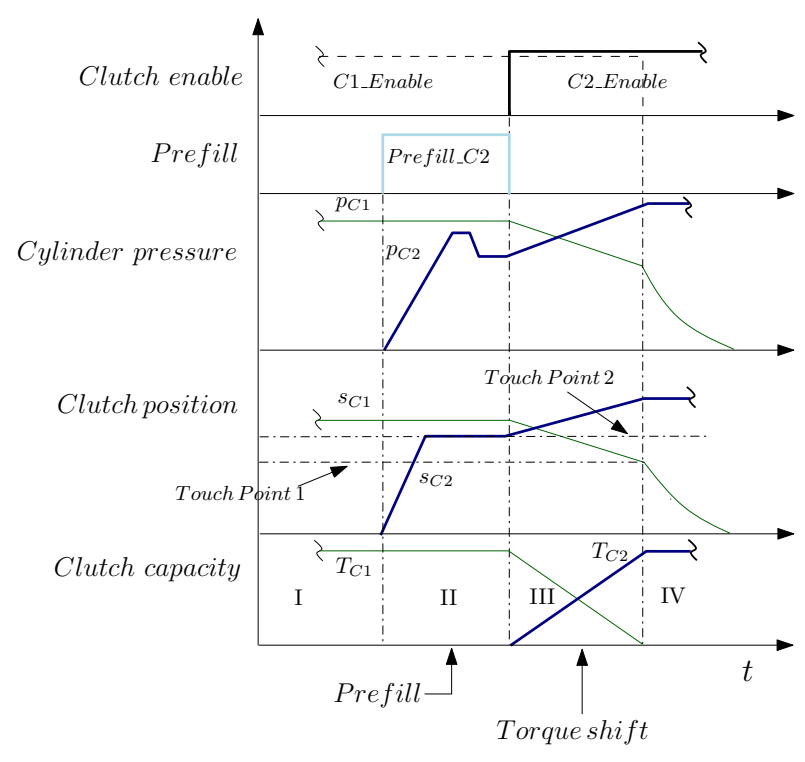

Figure 7: The basic function of the controller during build up and reduction of the clutch torque

into four stages (as shown in figure 7):

1. Clutch deactivation or relief condition (Phase I C1);

2. Pre-filling (Phase II - C2);

3. Clutch activation (Phase I, II, III - C1, or Phase III, IV - C2)

4. Emptying of the clutch cylinder (Phase IV - C1).

Figure 8 shows the control structure of the clutch. The output signals from the clutch model are cylinder pressure (p_Cyl_actual [bar]) and clutch position (s_C_actual $[\mathrm{m}]$ ). The command signal is the input for the clutch model. This signal is a normalized valve position signal (S_CCVx $[-1 \ldots 1])$, which is combined with a non-linear spool dynamics block. The spool dynamics block contains hysteresis, friction and a limit of the spool velocity [5]. The volume flow of the hydraulic oil is controlled by the spool position.

The inner loop is used to control the cylinder pressure and the outer loop controls the clutch position (as shown in figure 8). Both loops are realized by a PI controller. The control parameters for the inner loop circle have been empirically adjusted. The $T \Sigma$-method provides the opportunity for calculating the parameters of the outer loop circle [13]. To shorten the time for the parameter settings, the nonlinear system was linearized. With the linearized system the control parameter could be determined and it was possible to check the stability. 


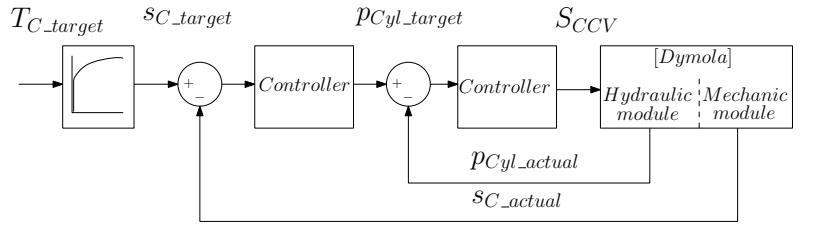

$S_{C C V}: \quad$ valve control signal $\quad[-1, \ldots, 1]$

$p_{\text {Cyl_target }}: \quad$ cylinder pressure (target) [bar]

$p_{\text {Cyl_actual }}$ cylinder pressure (actual) [bar]

$s_{\text {Cyl_target: }} \quad$ cylinder position (target) $[\mathrm{m}]$

$s_{\text {Cyl_actual }}$ cylinder position (actual) $[\mathrm{m}]$

Figure 8: The control design of the clutch model

The control strategy is based on a condition-based cascade control. This means that the pre-filling and the emptying of the clutch cylinder takes place only when the inner control system is active. If the clutch status is enabled, the overall cascade control system is in processing mode. To switch continuously from the "prefill" status to the "clutch enable" status, the start value of the integrator of the outer controller is set to the last pressure value of the pre-fill phase. An anti-windup process is used for counteracting the windup in the inner controller, after pressure emptying of the clutch cylinder. The valve control signal returns as quickly as possible to the operation state ( $S \_C C V x$ control signal is closed to zero) as shown in figure 10 . Additionally, a dither generator for the valve has been developed for overcoming the stick-slip-effect, which could occur due to the inaccuracy of the valve control.

\section{Simulation Results}

In section 2 the simulations model with the interface and the implemented control algorithm were presented. Now the clutch model, the suitable control algorithm, the performance and the functional capability of a basic shift strategy are shown in a simulation run. The simulation can be executed with a driver model, so it is possible to drive the driving cycles like the New European Driving Cycle (NEDC) [14]. The model inputs are a boolean ignition signal and two real values for the acceleration- and brake-pedal. Figure 9 shows the first simulation result containing the input signals accelerator-, throttle-position and the brake-pedal position. The throttle position is controlled by the engine control unit. The driver starts the engine with the ignition key. After the brake pedal is released by the driver and the acceleration pedal is pushed. This happens as long as the TCU has shifted up to the seventh gear. The second row of figure 9 shows the engine speed (n_Engine $[\mathrm{rpm}]$ ) and the speed of the two input shafts (n_Shaft1,n_Shaft2 [rpm]). The engine speed has to follow the torque transferring input shaft. If a higher gear is required, the synchronization releases the actual gear and engages the required one. This happens before the torque transfer begins. The next sub figure shows the induced engine torque with engagement (T_Engine_i $[\mathrm{Nm}])$, the engine torque (T_Engine $[\mathrm{Nm}]$ ) and the torque of the input shafts (T_Schaft1, T_Schaft2 $[\mathrm{Nm}]$ ). The next row of the figure illustrates the target clutch capacities (T_C1_target, $\mathrm{T}_{-} \mathrm{C} 2$ _target $[\mathrm{Nm}]$ ) and the actual clutch capacities (T_C1_actual,T_C2_actual $[\mathrm{Nm}]$ ). The last sub figure shows the signal desired gear and the current gear.

The vehicle accelerates and shifts up to the seventh gear. Each of these shift processes is accompanied by a continuous switch of the clutch capacities. The engine speed is reduced by the throttle position control, which is a submodule of the ECU. If sporty behavior is requested by the driver, the clutch control could be used to execute the speed-regulation. The engine intervention is controlled by the transmission control unit with a defined torque interface between these two control units. Figure 10 shows the detailed results of the third and the fourth gear for an up-shift process. On the left side the simulation results for the first clutch are shown. The right figure shows the results for the second clutch. In the first row, there are the normalized input signals of the hydraulic three port valves $\left(S_{-} C C V x[-1 \ldots 1]\right)$, followed by the results for the cylinder pressure signals (p_Cylx_actual [bar]). With the changing of the pressure signal there is a change in the position of the clutch $\left(\mathrm{s}_{\mathrm{Cx}}[\mathrm{m}]\right)$, which is shown in the next row of the results. In the last row, the target and the actual clutch capacity are shown (T_C1_target, T_C2_target $[\mathrm{Nm}]$ ).

The results of the simulations show the expected behavior for the hydraulic clutch system. The results especially show the relationship between the clutch position, cylinder pressure and clutch capacity. The quality of the model could not be determined without a comparison with measurements data from the transmission. The duration for the pre-fill function and the shift process is related to other DCT application [15].

\section{Summary and Outlook}

A detailed model of a hydromechanical double clutch actuator with a suitable control algorithm was presented. The model was integrated into a double clutch 

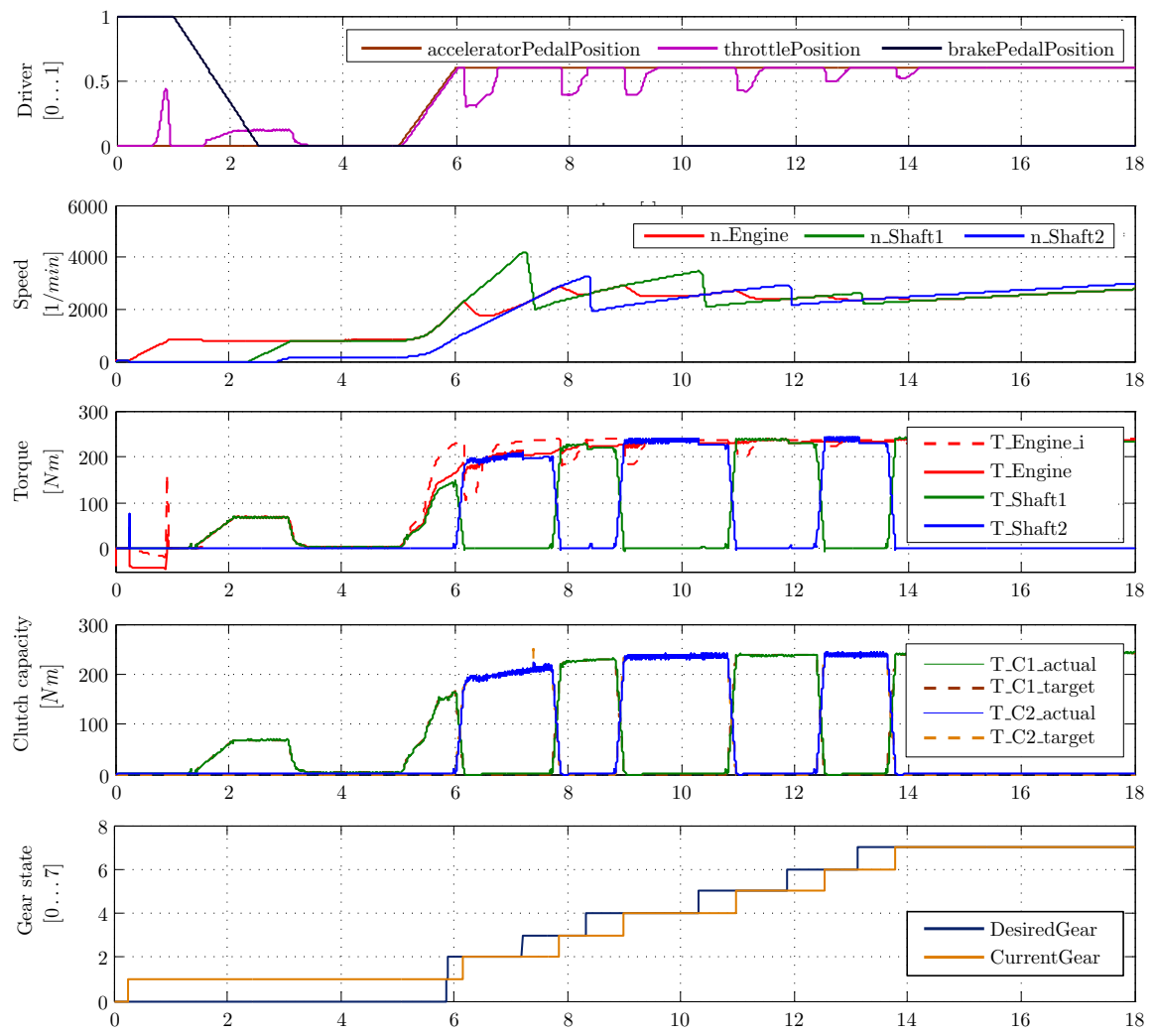

Figure 9: Simulation result of a up-shift cycle
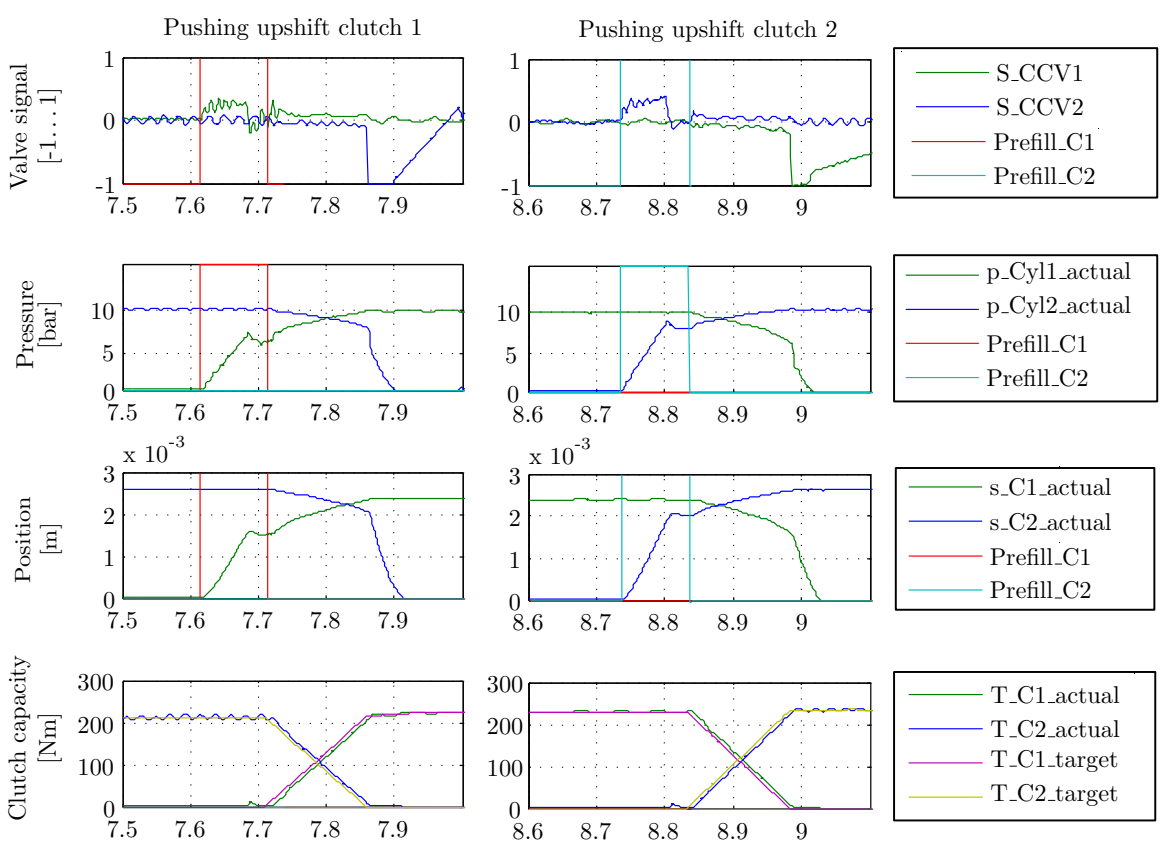

Figure 10: Detailed results of a shift process for the hydro-mechanic clutch actuator 
transmission model with seven speeds. The main focus was the modeling of the mechanical lever system. The detailed clutch model provides engineers the opportunity to develop new control algorithms in modelin-the-loop simulations. As example a cascaded PI controller was designed. The clutch model, the suitable control algorithm, the performance and the functional capabilities of a basic shift strategy were shown in a simulation run. The verification of the simulation models with the real transmission is in progress. Therefore a new transmission test bench at the TU Berlin, Chair of Electronic Measurement and Diagnostic Technology is used. At the moment the extensible hydraulic interface is used to implement a detailed synchronization model for the gear shift process. With this synchronization model in combination with the clutch model the calibration of the shifting and clutch algorithms in a model-in-the-loop simulation is feasible.

\section{References}

[1] U. Eggert, C. Kraus, M. Leibbrandt and K. Bernemann. The new family of Powershift Transmissions at GETRAG FORD Transmissions GmbH. In VDI Berichte 1943, Getriebe in Fahrzeugen 2006, page 289...308, Düsseldorf, 2006. VDI Verlag.

[2] S. Rinderknecht and U. Knödel. Evolution and Future Potential of Passenger Car Transmissions in Layshaft Design. In VDI Berichte 2029, Getriebe in Fahrzeugen 2008, Düsseldorf, 2008. VDI Verlag.

[3] C. Gühmann. Model-Based Testing of Automotive Electronic Control Units. In 3rd International Conference on Materials Testing: Test 2005, 2005. Nürnberg.

[4] H. Isernhagen and C. Gühmann. Modelling of a Double Clutch Transmission with an Appropriate Controller for the Simulation of Shifting Processes. In Bernhard Bachmann, editor, Proceedings of the 6th International Modelica Conference, pages 333-339, Bielefeld, Germany, 2008. Modelica Association and University of Applied Sciences Bielefeld.

[5] Hylib (2009), version 2.7. Product help, Modelon, 2009.
[6] G. Lechner, H. Naunheimer and S. Day. Automotive Transmissions: Fundamentals, Selection, Design and Application. Springer, Berlin, Heidelberg, New York, 1st edition, 1999.

[7] F. Rudolph, M. Schäfer, A. Damm, F.-T. Metzner and I. Steinberg. Das innovative 7-GangDoppelkupplungsgetriebe für die Kompaktklasse von Volkswagen. 28. Internationales Wiener Motorensymposium, 639:242-264, 2007.

[8] D. Findeisen. Ölhydraulik: Handbuch für die hydrostatische Leistungsübertragung in der Fluidtechnik. Springer, 2006.

[9] W. Staudt. Kraftfahrzeugmechatronik. Bildungsverl. EINS, 2007.

[10] U. Kiencke and L. Nielsen. Automotive Control Systems, For Engine, Driveline, and Vehicle. Springer, Berlin, Heidelberg, New York, 2nd edition edition, 2005.

[11] E. Kirchner. Leistungsübertragung in Fahrzeuggetrieben. Springer Verlag, Berlin, Heidelberg, New York, 2007.

[12] K. Reif. Automobilelektronik: Eine Einführung für Ingenieure. ATZ-MTZ-Fachbuch. Vieweg+Teubner, Wiesbaden, 3rd edition, 2009.

[13] L. Holger and W. Wendt. Taschenbuch der Regelungstechnik. Verlag Harri Deutsch, 2009.

[14] Emission Test Cycles. Summary of worldwide driving cycles. www.dieselnet.com/standards/cycles, 24.10 . 2010.

[15] R. Kubalczik, M. Ebenhoch and H. Schneider. 7-Gang Doppelkupplungsgetriebe für sportliche Anwendungen. In VDI Berichte 1943, Getriebe in Fahrzeugen 2006, page 309...324, Düsseldorf, 2006. VDI Verlag. 